\title{
Polymer-Drug Conjugates as Nanotheranostic Agents
}

\author{
Sajana Manandhar ${ }^{1,2,+} \oplus$, Erica Sjöholm ${ }^{2,+}$, Johan Bobacka ${ }^{1}\left(\mathbb{D}\right.$, Jessica M. Rosenholm ${ }^{2}(\mathbb{C}$ and \\ Kuldeep K. Bansal ${ }^{2, *(D)}$ \\ 1 Laboratory of Molecular Science and Engineering, Faculty of Science and Engineering, Johan Gadolin Process \\ Chemistry Centre, Åbo Akademi University, Biskopsgatan 8, 20500 Turku, Finland; \\ Sajana.Manandhar@abo.fi (S.M.); johan.bobacka@abo.fi (J.B.) \\ 2 Pharmaceutical Sciences Laboratory, Faculty of Science and Engineering, Åbo Akademi University, \\ Artillerigatan 6A, 20520 Turku, Finland; erica.sjoholm@abo.fi (E.S.); Jessica.Rosenholm@abo.fi (J.M.R.) \\ * Correspondence: kuldeep.bansal@abo.fi \\ + These authors contributed equally to the manuscript.
}

Citation: Manandhar, S.; Sjöholm, E.; Bobacka, J.; Rosenholm, J.M.; Bansal, K.K. Polymer-Drug Conjugates as Nanotheranostic Agents. J. Nanotheranostics 2021, 2, 63-81. https://doi.org/10.3390/jnt2010005

Academic Editor: Moein Moghimi

Received: 15 December 2020

Accepted: 9 March 2021

Published: 13 March 2021

Publisher's Note: MDPI stays neutral with regard to jurisdictional claims in published maps and institutional affiliations.

Copyright: (c) 2021 by the authors. Licensee MDPI, Basel, Switzerland. This article is an open access article distributed under the terms and conditions of the Creative Commons Attribution (CC BY) license (https:// creativecommons.org/licenses/by/ $4.0 /)$.

\begin{abstract}
Since the last decade, the polymer-drug conjugate (PDC) approach has emerged as one of the most promising drug-delivery technologies owing to several benefits like circumventing premature drug release, offering controlled and targeted drug delivery, improving the stability, safety, and kinetics of conjugated drugs, and so forth. In recent years, PDC technology has advanced with the objective to further enhance the treatment outcomes by integrating nanotechnology and multifunctional characteristics into these systems. One such development is the ability of PDCs to act as theranostic agents, permitting simultaneous diagnosis and treatment options. Theranostic nanocarriers offer the opportunity to track the distribution of PDCs within the body and help to localize the diseased site. This characteristic is of particular interest, especially among those therapeutic approaches where external stimuli are supposed to be applied for abrupt drug release at the target site for localized delivery to avoid systemic side effects (e.g., Visudyne ${ }^{\circledR}$ ). Thus, with the help of this review article, we are presenting the most recent updates in the domain of PDCs as nanotheranostic agents. Different methodologies utilized to design PDCs along with imaging characteristics and their applicability in a wide range of diseases, have been summarized in this article.
\end{abstract}

Keywords: polymer-drug conjugate; nanotheranostic; imaging; natural polymers; synthetic polymers; cancer

\section{Introduction}

Nanotechnology has been extensively applied in medical settings. The utmost advantage of nanoparticles is their size, usually ranging from 10 to $1000 \mathrm{~nm}$ in pharmaceutical applications, and the unique properties they acquire when entering this size range. Currently, polymer-based nanomedicines are rapidly developing, and especially polymer-drug conjugates (PDCs), also known as polymeric prodrugs or polymer therapeutics, fabricated as nanoparticles have gained much attention in the past decade. PDCs are a unique class of macromolecules prepared by using various chemical pathways that are dependent on the chemistry of both the drugs and the polymers [1]. The PDCs are made up of a polymeric backbone covalently linked to a drug with the aid of a linker and, in some cases, along with a targeting moiety. PDCs were first manufactured by utilizing a rational model developed by Helmut Ringsdorf in 1975 . This model comprises a biocompatible polymer backbone attached to three components: (1) a solubilizer that provides hydrophilicity, (2) a drug bound to the polymeric backbone via a linker, and (3) a targeting moiety that guides the PDCs to the desired physiological destination or bind to a particular biological target. Folic acid, engineered antibodies, sugars, and peptides are used as targeting moieties to improve the transportation of the conjugate to the targeted site [2]. Linkers serve as spacers that can be specifically cleaved and release the conjugated drug under certain conditions by specific 
stimuli. Different linkers, such as peptides, disulfides, hydrazine, and azo, have been used in the production of PDCs. The choice of linker affects the drug loading, stability, and release [3]. Attaching the drug to the polymer makes the drug inactive, a so-called prodrug, which is converted back into the active form in vivo by an exposure to internal or external stimuli cleaving the linker. The internal stimuli can be microenvironment stimuli such as $\mathrm{pH}$, redox environment, enzymes, hypoxic conditions, etc., whereas external stimuli utilized are, e.g., light, thermal, magnetism, and ultrasound [4].

There are three ways of manufacturing PDCs: (1) incorporation of a drug to a polymeric carrier, (2) incorporation of a drug to a monomer prior to polymerization, and (3) incorporation of a drug as monomers or initiators during the polymerization reaction. Controlled and high drug loading has been achieved with the second method; it has shown to not interfere with the polymerization or hinder the conjugation [5]. Several polymerization reactions have been used for the production of PDCs according to the second method and triggered drug release from conjugates loaded with multiple drugs has been acquired. By utilizing ring-opening polymerization (ROP), PDCs with biodegradable backbones have been obtained. However, while using ring-opening metathesis polymerization (ROMP) and reversible addition-fragmentation transfer polymerization (RAFT), some PDCs with non-biodegradable backbones have been produced [6].

Polymer conjugates are found to be capable of improving the pharmacokinetic parameters of the drugs, increasing the drug stability against degradation, providing high loading capacity, and sustained release patterns, as well as avoiding premature drug release. With the use of the polymer conjugate approach, it is possible to deliver both hydrophobic and hydrophilic drugs, which is usually difficult with drug-loaded nanoparticles prepared via physical encapsulation by utilizing hydrophobic interaction as the main mechanism. Considering the several advantages the PDCs holds, tens of such formulations are already in clinical trials $[7,8]$. For instance, products named NC-6300 and APL-2 are currently in clinical trials. NC-6300 is a novel nanoparticle formulation consisting of epirubicin hydrochloride covalently bound to block copolymer polyethylene glycol; poly-L-aspartic acid via an acid-labile hydrazine linker. Phase $\mathrm{Ib}$ trial had been conducted to determine the maximum tolerable dose (MTD) and recommended phase II dose (RP2D) of NC-6300 for metastatic solid tumors. The study showed that NC-6300 was well tolerated with manageable side effects along with a signal of preliminary activity observed in angiosarcoma [9]. APL-2 designed to target paroxysmal nocturnal hemoglobinuria has recently passed phase III studies. It consisted of a synthetic cyclic peptide, pegcetacoplan conjugated to polyethylene glycol that binds to $\mathrm{C} 3$ and $\mathrm{C} 3 \mathrm{~b}$ proteins. The study showed a significant improvement in hemoglobin level at 16 weeks compared to eculizumab (ClinicalTrials.gov Identifier: NCT03500549).

Polymer conjugates integrated with an imaging agent along with therapeutic drugs are known as theranostic agents due to the capability of providing both therapy and diagnosis or imaging functions integrated in a single system (Figure 1). Diagnosis/imaging provides information regarding the state of the target site and the drug, the drug's behavior, and the condition of the disease, whether it is progressing or deteriorating. Along with the treatment, diagnosis/imaging can be performed to retrieve information regarding the progression of the treatment. PDCs integrated with an imaging agent help monitor the drug's biodistribution and localization, which aid in a precise activation of a therapeutic response. Due to the versatile and tunable nature of polymer systems, the preparation of polymeric nanomedicine-based nanotheranostics turns out to be more facile [10].

Imaging techniques such as magnetic resonance imaging (MRI), computed tomography (CT), positron emission tomography (PET), single-photon emission computed tomography (SPECT), optical imaging (fluorescence and bioluminescence), two-photon excited fluorescence (TPEF), and photoacoustic imaging (PAI) are the currently used techniques for biomedical and medical imaging [11]. The different imaging techniques have different abilities to reveal structural and/or functional information at different scales and accuracy levels. MRI shows high spatial resolution with no depth limit and does not utilize radia- 
tion, but it has poor sensitivity to probes and is expensive to use. CT as MRI exhibits high resolution and no depth limitation, but requires radiation, has poor soft tissue delineation, and MRI exhibits low sensitivity to probes. Nuclear imaging, including PET and SPECT, has a high sensitivity to probes, but they exhibit low resolution, need for radiation, and are expensive to use. Optical imaging, including fluorescence and bioluminescence, provides multichannel imaging, does not require radiation, and exhibits high sensitivity to the probe dose, but has low depth penetration and resolution [12]. With TPEF, deeper tissue penetration is obtained compared to conventional optical imaging, but the required high intensities can lead to cell destruction [13]. PAI again exhibits high tissue penetration, high resolution, and no radiation is required, but it is temperature dependent, has limited path length, and a weak absorption at short wavelengths [14].

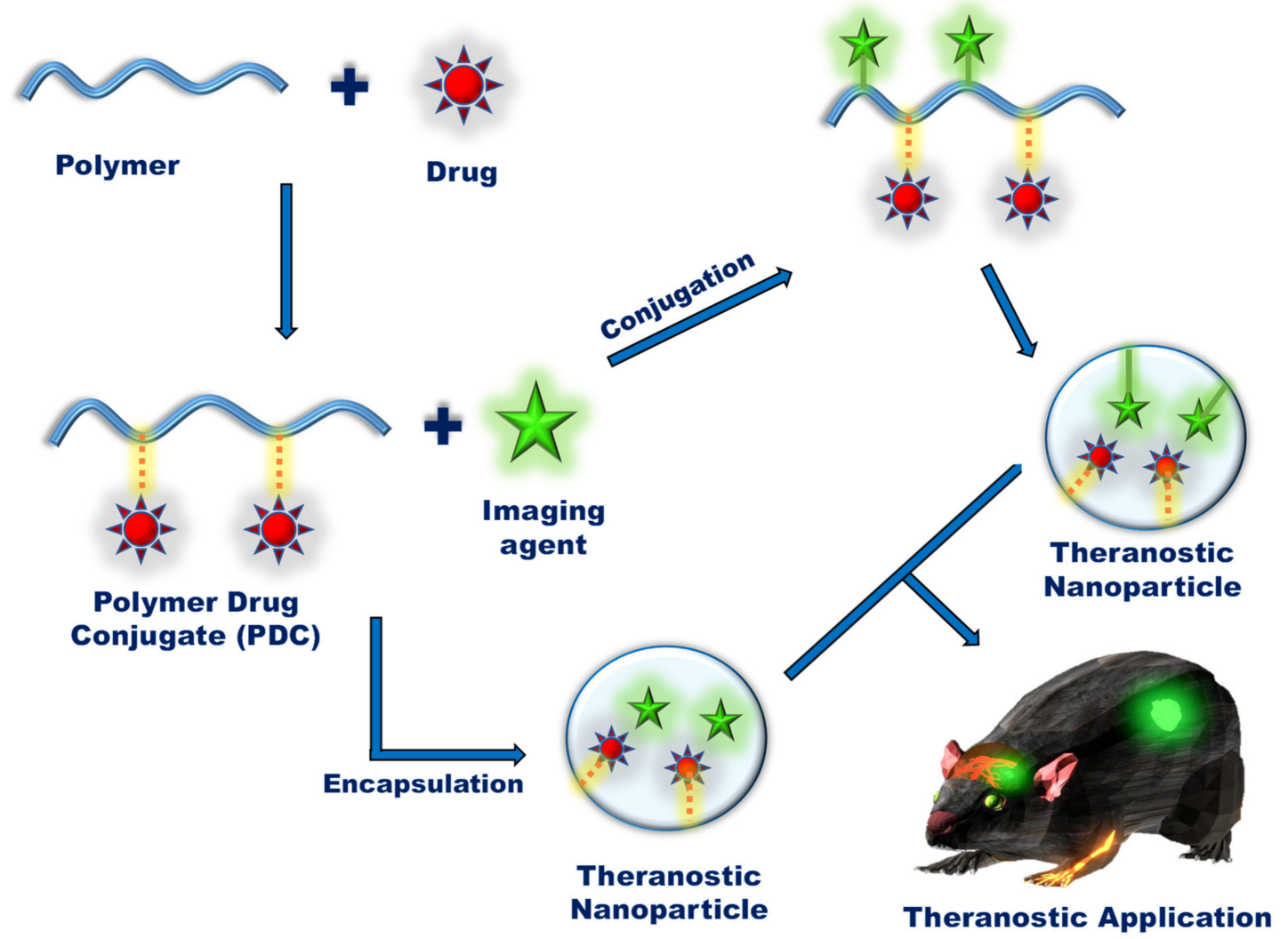

Figure 1. A general overview of the preparation of polymer-drug conjugate-based theranostic nanoparticles.

Different types of polymeric materials are used to develop theranostic agents based on the kind of functional group and properties of the materials intended for imaging/diagnosis and therapy. Most common imaging agents include photoluminescence with a fluorescent group, quantum dots, magnetic compounds, and contrast agents for magnetic resonance imaging (MRI). Common therapeutic strategies include drug delivery, gene delivery, photodynamic therapy, hyperthermia, and radiation therapy. Cancer, Alzheimer's disease, genetic disorders like adenosine deaminase deficiency, cystic fibrosis, familial hypercholesterolemia, hereditary hemochromatosis, antitrypsin deficiency, and ornithine transcarbamylase deficiency are the most common disorders where the nanotheranostic approach have been successfully utilized [15].

In this review, we have compiled the recent advances accomplished in the field of nanotheranostics using PDCs with the focus on studies published in the last five years. The preparation, advantages, applications, and limitations of PDCs have been exhaustively reviewed previously $[2,8,16,17]$, and these aspects are thus excluded from this review. We are presenting an overview of the different PDCs that have been designed and successfully 
implemented for both therapy and diagnosis. We are also providing insight into different types of polymers and imaging agents utilized for the fabrication of nanotheranostic PDCs.

\section{Polymers Used in Nanotheranostics}

Various polymers are being studied for the development of polymer-drug conjugates as nanotheranostics. The free functional groups present on the polymer chain offer the possibility to be coupled with different agents such as therapeutic, imaging, and targeting moieties, which in turn makes them a promising material for nanotheranostic applications $[18,19]$. Both synthetic and natural polymers are used for the formulation of PDCs [18]. Synthetic polymers for formulating PDCs include poly $\mathrm{N}$-(2hydroxypropyl)-methacrylamide-(poly-HPMA), polyethylene glycol (PEG), polylactic acid (PLA), poly(lactic-co-glycolicacid) (PLGA), polyphosphazene, polyphosphoesters (PPEs), and polyglycerol. Polyglutamic acid, albumin, gelatin, alginate, chitosan, hyaluronic acid, and hydroxyethyl starch are examples of natural polymers that have been explored for the preparation of PDCs. Natural polymers are the most abundant and biodegradable polymers, but batch-to-batch variations (reproducibility) and microbial contamination (purity) leading to source-related transmission risk are often observed within this class of polymers. In most cases, additional purification steps to generate pure polymers lead to a significant cost rise. Further, natural polymers, in general, are less stable compared to synthetic polymers and their degradation rate in vivo largely depends on the biological location [20,21]. The detailed advantages and limitations of polymers often used for fabricating PDCs are given in Table 1. In recent years, biodegradable and biocompatible polymers have become the prime choice for the preparation of PDCs. Biocompatibility prevents undesirable interactions in the body, whereas biodegradability ensures the excretion of the polymer after breakdown into small monomers from the body. Recent PDC-based nanotheranostic materials are summarized in Table 2.

Table 1. Advantages and disadvantages of polymers, which are often utilized to fabricate polymer-drug conjugates.

\begin{tabular}{|c|c|c|c|c|c|}
\hline S. No. & Polymer Name & Structure & Advantages & Disadvantages & References \\
\hline 1 & poly-HPMA & & $\begin{array}{l}\text { Biocompatible, } \\
\text { hydrophilic, } \\
\text { non-immunogenic }\end{array}$ & $\begin{array}{l}\text { Non-biodegradable, } \\
\text { broad polydispersity } \\
\text { index }\end{array}$ & [22] \\
\hline 2 & PEG & & $\begin{array}{l}\text { Biocompatible and } \\
\text { hydrophilic, soluble in } \\
\text { common organic } \\
\text { solvents, polymer with } \\
\text { stealth behavior }\end{array}$ & $\begin{array}{l}\text { Non-biodegradable, } \\
\text { immunogenic, limited } \\
\text { conjugation sites }\end{array}$ & {$[23,24]$} \\
\hline 3 & PLA & & $\begin{array}{l}\text { Biodegradable, } \\
\text { biocompatible, } \\
\text { renewable }\end{array}$ & $\begin{array}{l}\text { Slow degradation, } \\
\text { acidic degradation } \\
\text { product, hydrophobic, } \\
\text { limited conjugation } \\
\text { sites, tissue reaction at } \\
\text { the injection site }\end{array}$ & {$[25,26]$} \\
\hline 4 & PLGA & & $\begin{array}{l}\text { Biodegradable, } \\
\text { biocompatible, } \\
\text { renewable with tunable } \\
\text { properties }\end{array}$ & $\begin{array}{l}\text { limited conjugation } \\
\text { sites, acidic degradation } \\
\text { product, tissue reaction } \\
\text { at the injection site }\end{array}$ & {$[27,28]$} \\
\hline 5 & Polyphosphazene & & $\begin{array}{l}\text { Biocompatible, } \\
\text { biodegradable, } \\
\text { multifunctional }\end{array}$ & $\begin{array}{l}\text { Complicated synthesis } \\
\text { procedure of functional } \\
\text { polymers, high } \\
\text { production cost }\end{array}$ & {$[29,30]$} \\
\hline 6 & Polyphosphoesters & & $\begin{array}{l}\text { Biocompatible, } \\
\text { biodegradable, stealth } \\
\text { property, hydrophilic, } \\
\text { multifunctional }\end{array}$ & $\begin{array}{l}\text { High production cost, } \\
\text { limited in vivo data }\end{array}$ & {$[31,32]$} \\
\hline 7 & Polyglycerol & & $\begin{array}{l}\text { Hydrophilic, } \\
\text { biocompatible, low } \\
\text { toxicity and } \\
\text { immunogenicity, } \\
\text { antifouling property }\end{array}$ & $\begin{array}{l}\text { Difficult to control the } \\
\text { degree of branching, } \\
\text { molecular weight, and } \\
\text { polydispersity, } \\
\text { non-biodegradable }\end{array}$ & {$[33,34]$} \\
\hline
\end{tabular}


Table 1. Cont.

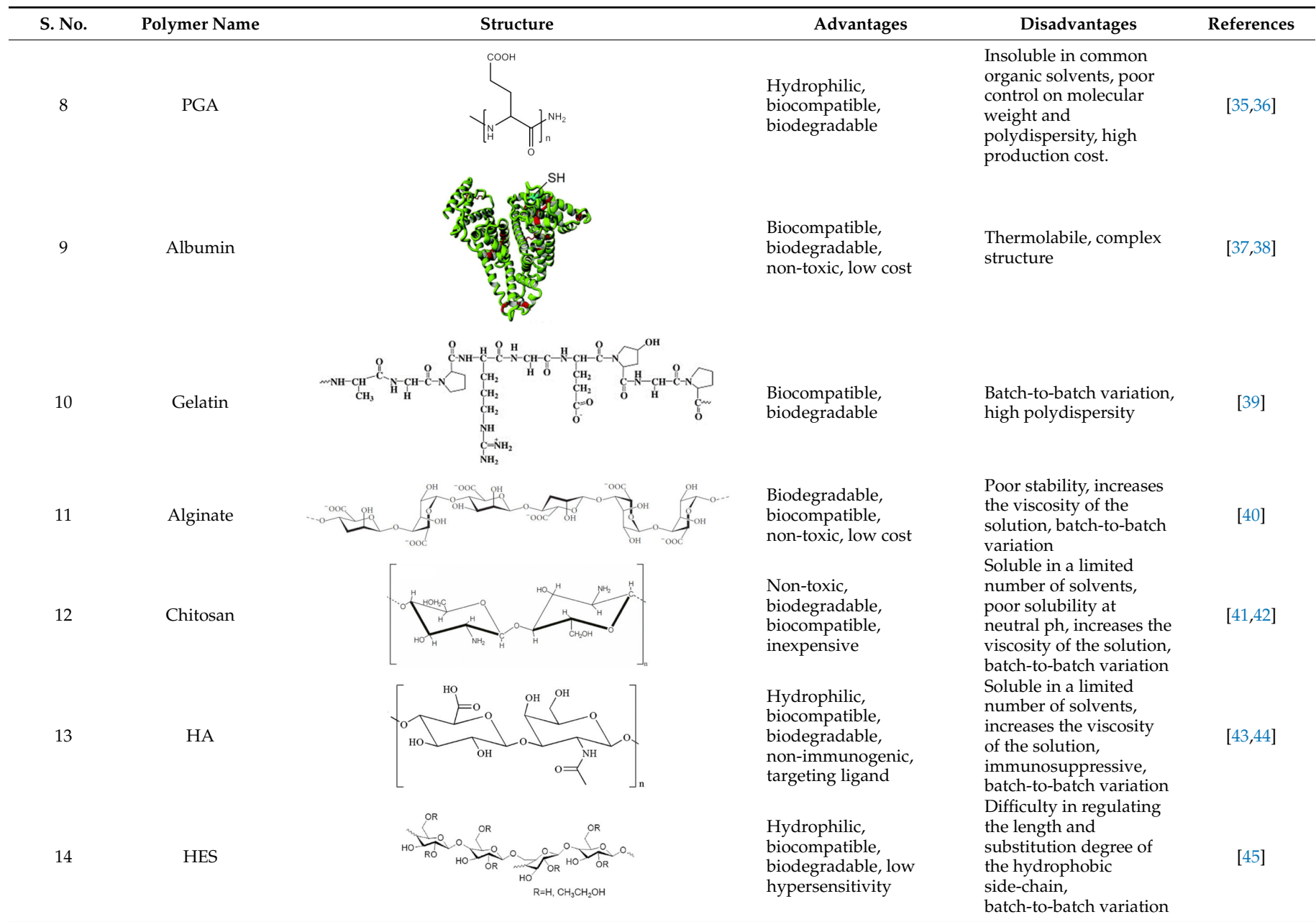

Poly-HPMA—poly N-(2-hydroxypropyl) methacrylamide, PEG—poly(ethylene glycol), PLA—poly(lactic acid), PLGA—poly(lactic coglycolic acid), PGA—poly(glutamic acid), HA—hyaluronic acid, HES-hydroxyethyl starch.

\subsection{Synthetic Polymers in Nanotheranostic Agent Design}

2.1.1. Poly $N$-(2-Hydroxypropyl)-methacrylamide

Poly N-(2-hydroxypropyl)-methacrylamide (poly-HPMA) is a hydrophilic, linear, nontoxic, biocompatible, and non-immunogenic polymer used for the formulation of PDCs. HPMA copolymers contain multiple reactive groups that can be used to attach therapeutic, imaging, and targeting moieties, making it a potential polymer for nanotheranostic applications. Reactive functional groups commonly used for conjugation are amines, esters, imides, and phenol residues [46]. Poly-HPMA-based PDCs with nanotheranostic characteristics are widely reported in the literature. For instance, Koziolova et al. designed novel PDCs, i.e., Zirconium $89\left(\mathrm{Zr}^{89}\right)$ labeled HPMA-doxorubicin (DOX) copolymer conjugates. HPMA copolymers differing in molecular weight were synthesized either by FRP or by RAFT polymerization. The drug was bound to the poly-HPMA by $\mathrm{pH}$-sensitive hydrazone bonds. The polymer conjugates with $\mathrm{DOX}$ by a reaction between the $\mathrm{C} 13$ keto group of $\mathrm{DOX}$ and the hydrazide group of the polymer precursor or copolymer, forming a $\mathrm{pH}$ sensitive hydrazone bond. The PDCs were then radiolabeled with $\mathrm{Zr}^{89} \cdot \mathrm{Zr}^{89}$ could provide excellent radio stability, an important feature required for PET. They also formulated dyeconjugated PDCs, and the feasibility of the two imaging techniques, fluorescence imaging (FI) and PET, was compared. DY-633-NHS-ester and DY-676-NHS-ester fluorescent dyes were conjugated. They found the results from both techniques to be comparable. In this work, they studied the influence of the molecular weight and the dispersibility of HPMA copolymers on the biodistribution using FI and PET. The relatively low positron energy 
and long half-life of $\mathrm{Zr}^{89}$ allowed the observation of their biodistribution for up to $72 \mathrm{~h}$. The poly-HPMA conjugates of low polydispersity $(\mathrm{D}=1.1)$ with a molecular weight close to the renal threshold $(45 \mathrm{~kg} / \mathrm{mol})$ prepared by RAFT polymerization showed increased cellular uptake and cytotoxicity to cancer cells [47]. However, the availability of $\mathrm{Zr}^{89}$ is limited, and it has high gamma energy emission at $908.97 \mathrm{keV}$; therefore the dose should be limited for administration [48].

A second generation HPMA copolymer-epirubicin (EPI) diblock conjugate (2P-EPI) was designed and synthesized by Yang et al. for the treatment of ovarian cancer with the capacity for non-invasive fate monitoring. The diblock conjugates were synthesized by RAFT polymerization using a bifunctional chain transfer agent (Peptide2CTA). The polymer backbone was labeled with an acceptor fluorophore $\mathrm{Cy} 5$, while donor fluorophores (Cy3 or EPI) were attached to the HPMA copolymer side chains via enzyme cleavable glycyl-phenylalanyl-leucyl-glycyl (GFLG) linker. The fate of the drug and the polymer backbone was elucidated using fluorescence resonance energy transfer (FRET) imaging. The pharmacokinetic (PK) and the therapeutic effect of the 2P-EPI conjugate were compared to that of the 1st generation (1P-EPI) conjugate. The 1P-EPI was non-biodegradable and had a molecular weight lower than the renal threshold. The 2P-EPI showed an increased PK of about four-folds attributed primarily to an increased molecular weight of the polymeric carrier. Furthermore, it showed a complete tumor remission and long-term inhibition of tumorigenesis (100 days) [49].

Table 2. Summary of recent PDC-based nanotheranostic materials including the investigated drug, method of conjugation, integrated imaging agent, and indication.

\begin{tabular}{|c|c|c|c|c|c|}
\hline Polymer & Drug Used & Method of Drug Conjugation & Imaging Agent & Indication & Reference \\
\hline poly-HPMA & Doxorubicin & $\begin{array}{l}\text { pH-sensitive hydrazone bond } \\
\text { formation }\end{array}$ & $\begin{array}{c}\text { Zirconium } 89^{\mathrm{C}} \text { and } \\
\text { dye(DY-633 andDY-676) }{ }^{\mathrm{C}}\end{array}$ & Cancer & [47] \\
\hline poly-HPMA & Epirubicin & $\begin{array}{l}\text { Copolymerization of HPMA with } \\
\text { GFLG-EPI }\end{array}$ & Cy 5 Fluorophore ${ }^{\mathrm{C}}$ & Ovarian cancer & [49] \\
\hline poly-HPMA & Pyropheophorbide & Amide bond & \multirow{2}{*}{$\begin{array}{c}\text { Pyropheophorbide }{ }^{\mathrm{C}} \\
\text { Cyanine } 5.5 \text { and Gadolinium } \\
\text { (III) }{ }^{\mathrm{C}}\end{array}$} & Cancer & {$[50]$} \\
\hline poly-HPMA & Paclitaxel & GFLG linker & & Breast cancer & {$[51]$} \\
\hline PEG & Chlorine e6 & \multirow{2}{*}{$\begin{array}{c}\text { Disulfide linker } \\
\text { Succinimidyl-3-(2-pyridyldithio)- } \\
\text { propionate (SPDP) } \\
\text { linker }\end{array}$} & Chlorine e ${ }^{\mathrm{C}}$ & Cancer & {$[52]$} \\
\hline PEG & Mertansine & & Gallium $68^{\mathrm{C}}$ & Prostate cancer & [53] \\
\hline Methoxy PEG & Monomethyl auristatin E & $\begin{array}{c}\text { Reductive sensitive and } \\
\text { self-immolative linker }\end{array}$ & Cyanine $7.5^{\mathrm{C}}$ & Cancer & {$[54]$} \\
\hline PLA & Doxorubicin & Hydrazone linker & Rhodamine B (RhB) ${ }^{C}$ & Cancer & [55] \\
\hline PLGA & Methotrexate & Ethylenediamine linker & 1-pyrenebutyric acid ${ }^{\mathrm{C}}$ & Cancer & [56] \\
\hline Polyphosphazene & Docetaxel & Aconitic acid linker & Cyanine dye ${ }^{\mathrm{C}}$ & Cancer & [57] \\
\hline Polyphsphoesters & Doxorubicin & Thioketal linker & Chlorin e6 ${ }^{\mathrm{E}}$ & Cancer & [58] \\
\hline Polyglycerol & Doxorubicin & $\begin{array}{c}\mathrm{pH} \text {-sensitive linker/enzyme } \\
\text { sensitive linker }\end{array}$ & Doxorubicin $^{\mathrm{C}}$ & Cancer & [59] \\
\hline PGA & Porphyrin & $\begin{array}{l}\text { Ring-opening polymerization } \\
\text { (amide bond) }\end{array}$ & Porphyrin ${ }^{\mathrm{C}}$ & Cancer & {$[60]$} \\
\hline PGA & Doxorubicin & Carbodiimide coupling & Tc- $99 \mathrm{~m}^{\mathrm{C}}$ & Cancer & {$[61]$} \\
\hline Albumin & Chlorine e6 & Carbodiimide coupling & $\begin{array}{l}\text { Iridium oxide, manganese } \\
\text { dioxide }^{\mathrm{E}}\end{array}$ & Cancer & {$[62]$} \\
\hline Albumin & Doxorubicin & $\begin{array}{l}\text { Maleimide-sulfhydryl/Schiff } \\
\text { base }\end{array}$ & Gadolinium (III) ${ }^{\mathrm{C}}$ & $\begin{array}{c}\text { Triple-negative breast } \\
\text { cancer }\end{array}$ & [63] \\
\hline Gelatin & Porphyrin & Amide coupling & Porphyrin ${ }^{\mathrm{C}}$ & Antibiotic resistance & [64] \\
\hline Alginate & Kinase inhibitor (PI103) & Adamantane-Inclusion complex & 5FAM ${ }^{\mathrm{C}}$ & Cancer & [65] \\
\hline Alginate & Doxorubicin & Acid-labile Schiff base & Fluorescent carbon dots ${ }^{\mathrm{C}}$ & Cancer & {$[66]$} \\
\hline Chitosan & Pyropheophorbide & Carbodiimide coupling & Fluorescein isothiocyanate ${ }^{\mathrm{C}}$ & Cancer & {$[67]$} \\
\hline Chitosan & Bilirubin, losartan & Carbodiimide coupling & MHI- $148^{\text {C }}$ & Hepatic fibrosis & {$[68]$} \\
\hline Chitosan & Doxorubicin & $p$-carboxybenzaldehyde linker & Doxorubicin & Cancer & [69] \\
\hline HA & Gemcitabine & Carbodiimide coupling & $\mathrm{THP}^{\mathrm{C}}$ & Cancer & [70] \\
\hline HA & Prussian Blue & Carbodiimide coupling & $\begin{array}{c}\mathrm{Fe}_{3} \mathrm{O}_{4} \mathrm{E} \\
\text { Quantom dots } \mathrm{C}\end{array}$ & Cancer & [71] \\
\hline HES & Paclitaxel & Disulfide linker & $\mathrm{DiR}^{\mathrm{E}}$ & Cancer & [72] \\
\hline HES & Doxorubicin & Disulfide linker & $\mathrm{ICG}^{\mathrm{E}}$ & Cancer & [73] \\
\hline
\end{tabular}

How the imaging agent was combined to the PDC: ${ }^{\mathrm{C}}$ conjugated, and ${ }^{\mathrm{E}}$ encapsulated. 
Fang and his group synthesized HPMA pyropheophorbide-a(P-PyF) conjugates for photodynamic therapy (PDT) and photodynamic diagnostics (PDD). Polymer precursor poly-HPMA was synthesized by RAFT copolymerization. The conjugates were formed by the reaction of pentafluorophenyl ester of $\mathrm{PyF}$ with the polymer precursor. The PyF was conjugated to poly-HPMA by an amide bond. The mean particle size of P-PyF was about $200 \mathrm{~nm}$. PyF is a potent photosensitizer having high PDT efficacy and imaging potency. Photosensitizers are compounds that could be irradiated to release reactive oxygen species (ROS), namely singlet oxygen $\left({ }^{1} \mathrm{O}_{2}\right)$ that kill tumor cells. In aqueous solutions, P-PyF formed micelles, showing prolonged circulation time. Based on enhanced permeability and retention effect (EPR), accumulation of P-PyF occurred at the tumor site [74,75]. The micellar structure was intact in the circulation because of little ${ }^{1} \mathrm{O}_{2}$ generation, whereas disruption of micelles occurred in the tumor environment upon irradiation at about $420 \mathrm{~nm}$. As the micelles disrupted, high fluorescence could be observed along with the generation of ${ }^{1} \mathrm{O}_{2}$ resulting in cytotoxicity. Irradiation at a longer wavelength at about $680 \mathrm{~nm}$ exhibited remarkable tumor imaging with little autofluorescence of background. This formulation could effectively work for PDT/PDD using two different wavelengths for treatment and imaging, respectively [50].

Hao et al. designed and studied a novel amphiphilic biodegradable HPMA copolymergadolinium-paclitaxel-cyanine 5.5 (pHPMA-Gd-PTX-Cy5.5) conjugate for theranostic applications. The amphiphilic block polymer was synthesized through a two-step RAFT polymerization, and nanoparticles were formed by self-assembly in aqueous solution. The size of the nanoparticles was around $85 \mathrm{~nm}$. The enzyme-sensitive tetrapeptide GFLG was used as a linker for conjugation of the polymeric backbone and paclitaxel (PTX). The Cy5.5 and $\mathrm{Gd}(\mathrm{III})$-labeled nanoparticles had five-fold magnetic relaxivity compared to that of a clinical MRI contrast agent, Gd-DTPA. In vivo MRI, FI, and Gd (III) histological distribution, demonstrated the prolonged residence time of the nanoparticles with increased accumulation at the tumor site. The conjugate-based nanoparticles could significantly inhibit proliferation and induced apoptosis of the tumor cells, and no obvious side effects were observed. The formulated PDCs could effectively work as therapeutic and MR imaging of cancer cells [51].

\subsubsection{Polyethylene Glycol}

Polyethylene glycol (PEG) is a biocompatible, non-immunogenic, and non-antigenic polymer with high water solubility. It is readily cleared from the body, and it is the polymer of choice for drug conjugation. PEGylation is a popular strategy that involves conjugation of PEG with a therapeutic agent [2]. PEGylation improves the water solubility of hydrophobic drugs, prolongs the circulation time, minimizes nonspecific uptake, and provides specific tumor-targeting ability by EPR effect. PEG has limited conjugation capacity since it has only one terminal functional group at the end of the polymer chain (two in the case of modified PEG). This limitation is proposed to be overcome by coupling amino acids like aspartic acids and bicarboxylic amino acid to the PEG [76]. Another limitation of PEG is that it is non-biodegradable, resulting in possible accumulation in the body if the size of the nanoparticles are greater than the renal threshold [2].

Studies have shown that simple conjugation of hydrophilic PEG with hydrophobic drug molecules results in the formation of nanoparticles by self-assembly [77,78]. Hou et al. designed a unique matrix metalloproteinase 2 (MMP2)-targeted photosensitizer delivery platform for tumor targeting imaging and PDT. The photosensitizer chlorine e6 (Ce6) was covalently conjugated with the MMP2-targeted cleavable polypeptide and then later attached to PEG by a redox-responsive cleavable disulfide linker. The size of PEG-SS-Ce6-MMP2-based nanoparticles was about $123 \mathrm{~nm}$, and due to the presence of a disulfide linker, the nanoparticles demonstrate a rapid release of Ce6 upon exposure to glutathione (Figure 2). The synthesized PDCs were claimed to have enhanced internalization and uncompromised phototoxic effect toward tumors compared to free Ce6 and PEGylated Ce6 PDCs. The PEG-SS-Ce6-MMP2 PDCs showed a noticeable increase 
in tumor-targeting ability and a significantly improved PDT. The intrinsic fluorescence of Ce6 upon IR irradiation was used for imaging the in vivo biodistribution of free Ce6, PEG-SS-Ce6, and PEG-SS-Ce6-MMP2 PDCs using the fluorescence imaging technique [52].

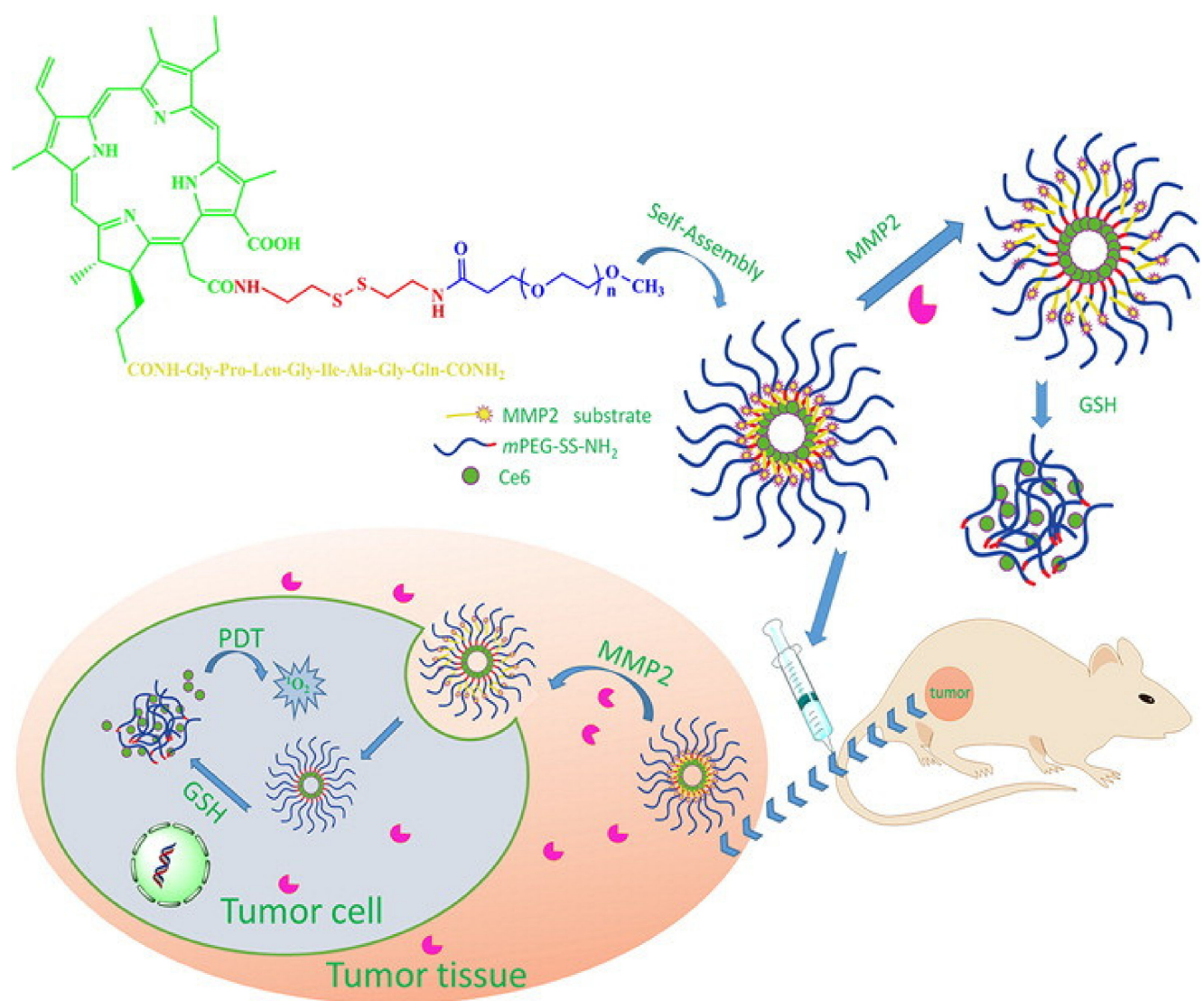

Figure 2. Schematic illustration of the preparation of the PEG-SS-Ce6-MMP2 nanoparticles and their applications in vivo. Reproduced with permission from Reference [52]. Copyright (2016) American Chemical Society.

Kumar et al. reported a theranostic design of small-molecule drug conjugates (TSMDCs) for targeted imaging and chemotherapy. PEG was used as a polymeric carrier. A chelating moiety labeled with Gallium $68\left(\mathrm{Ga}^{68}\right)$ was used as an imaging agent for PET. The conjugate also incorporated prostate-specific membrane antigen (PSMA) for prostate cancer targeting and mertansine (DM1) as a cytotoxic drug. Succinimidyl 3-(2pyridyldithio) propionate (SPDP) was used as a linker. The formulated T-SMDCs could retain the PSMA binding affinity and express PSMA-dependent toxicity. By incorporating Ga 68-labeling, imaging of PSMA-expressing cancer xenografts in mice was possible [53].

Qi et al. synthesized a novel triblock copolymer of methoxypoly(ethyleneglycol)-blockpoly(carbobenzyloxy-L-lysine)-block-poly\{N-[N-(2-aminosthyl)-2-aminosthyl]aspartamide $\}$ (mPEG-b-PZLL-b-PASP(DET)) that could self-assemble into a biodegradable nanoparticle with a hydrophilic mPEG surface, a hydrophobic PZLL core, and a cationic polypeptide corona comprised of PASP(DET). The triblock copolymer was synthesized by ROP. Antimitotic agent monomethyl auristatin E (MMAE) was conjugated to the PASP(DET) block by a reductive sensitive and self-immolative linker. Cyanine 7.5 was used for imaging of in vivo distribution. The MMAE-conjugated nanoparticles were able to double the duration of tumor growth inhibition in comparison to cisplatin [54]. 


\subsubsection{Polylactic Acid}

Polylactic acid (PLA) is an aliphatic polyester with high biocompatibility and biodegradability. PLA has been investigated as an efficient carrier of various contrast and therapeutic agents [46].

Hu et al. successfully prepared multifunctional micelles by co-assembling three different PDCs. They co-assembled a DOX-conjugated polymer (mPEG-b-PLA-co-mercaptoethanole (ME)/DOX) and a Rhodamine B(RhB)-conjugated copolymer (mPEG-b-PLA-co-ME/RhB) with a folic acid (FA)-conjugated copolymer (FA-PEG-b-PLA). The FA-conjugated copolymer acted as a targeting agent, and $\mathrm{pH}$-sensitive hydrazone was used as a linker. The sizes of these micelles were in the range of 150-300 nm. The fluorescent imaging analysis of RhB signals showed that FA-carrying micelles were retained in the tumor for a more extended period than those without FA moieties [55].

\subsubsection{Poly(Lactic-co-glycolic Acid)}

Poly(lactic-co-glycolic acid) (PLGA) is a biocompatible polyester. PLGA is produced by a catalyzed ring-opening copolymerization of lactic acid (LA) and glycolic acid (GA). PLGA is a semicrystalline material with hydrophobic properties, and it degrades readily under physiological conditions. PLGA being the copolymer of PGA and PLA, possesses the characteristics of its constitutional monomers and is most often used where the disadvantages of PLA, such as prolonged degradation time and weak mechanical strength, limit its applications [79].

Chatterjee et al. proposed a novel synthesis of 1-pyrenebutyric acid (PBA)-conjugated PLGA polymer using ethylenediamine (EDA) as a linker fabricated as a stable fluorescent nanoparticle. An antimetabolite of folic acid, methotrexate (MTX) was conjugated on the surface of the synthesized PLGA-PBA nanoparticles by using an EDA linker to kill the cancer cells. The size of the nanoparticles was about $105 \mathrm{~nm}$, and the zeta potential was $-38.5 \mathrm{mV}$. The nanoparticles could provide stable fluorescence for in vitro monitoring of the therapeutic effect. Significant internalization of the nanoparticles was observed in cancer cells. Since MTX is an analog of folic acid, it could increase the cells' internalization through the folate receptor $(\mathrm{FR} \alpha)$. It was also observed that a higher amount of PLGAPBA-MTX PDCs was found in MTX-resistant cancer cells than those of non-resistant cancer cells. The nanoparticles were also sensitive to acidic $\mathrm{pH}$, showing high drug release in acidic medium. Elevated apoptosis from the nanoparticles was observed compared to free MTX [56].

\subsubsection{Polyphosphazene}

Polyphosphazenes are a new class of hybrid polymers composed of a flexible inorganic backbone of alternating phosphorous and nitrogen with two organic side groups $\left(R, R^{\prime}\right)$ and are represented by $\left[N=P(R)\left(R^{\prime}\right)\right]$ formula. Polyphosphazene is a versatile biodegradable polymer. The versatility is due to the presence of two chlorine atoms attached on both sides of the phosphorus atom of its polymeric backbone, and it can be easily replaced by nucleophilic substitution. Polyphosphazene has also been explored for the formulation of polyphosphazene-drug conjugates [29].

Yong et al. successfully designed a new biocompatible drug-delivery system comprising phosphazene conjugation with the hydrophobic drug docetaxel (DTX). A hydrophilic methoxy-PEG with an average molecular weight of 550 (MPEG550) was attached to the polyphosphazene backbone as a side group $\mathrm{R}$ for prolonged blood circulation along with a multifunctional amino acid lysine ethylester (LysOEt) as another side group $\mathrm{R}^{\prime}$ for direct conjugation with DTX. DTX was conjugated to the carrier polymer by acid cleavable cis-aconitic acid (AA). They formulated an amphiphilic conjugate [NP(MPEG550) 3 (LysOEt(AA)(DTX) $]_{n}$ that could self-assemble into stable polymeric micelles and named it as "polytaxel." The size of the conjugate was about $41.3 \mathrm{~nm}$. Polytaxel was labeled by cyanine dye, and ex vivo imaging showed that intravenously injected Polytaxel has a longer circulation in the bloodstream and can selectively accumulate in tumor tissues. The 
study on mice against the human gastric tumor cell line showed complete tumor regression with low systemic toxicity [57].

\subsubsection{Polyphosphoesters}

Polyphosphoesters (PPEs) consist of repeating phosphoester bonds in the polymeric backbone. PPEs are very versatile polymers that are biocompatible and biodegradable through hydrolysis as well as enzymatic digestion under physiological conditions. They are similar to biomacromolecules such as nucleic acid and are very useful for biological applications. PPEs contain phosphorous atoms that allow the introduction of bioactive molecules [80].

Pei et al. introduced a ROS-sensitive DOX and PPE conjugate. The copolymer of the polyphosphoester was synthesized by ROP of the cyclic phosphoester monomers. A thioketal (TK) linker was used for conjugation. Ce6 was encapsulated during the selfassembly of the nanoparticles in the aqueous solution. The obtained Ce6@PPE-TK-DOX nanoparticles prevented premature drug release completely during blood circulation. The particle size of the nanoparticles was about $73 \mathrm{~nm}$. Upon illumination at the tumor area under the guidance of fluorescence/MR dual-model imaging, ROS was generated, resulting in the rapid cleavage of the TK bond. DOX was locoregionally released and activated, indicating tumor-specific drug delivery. The phototriggered drug release and activation at the desired site could provide efficient and targeted drug delivery and enhanced therapeutic effect with minimum side effects [58].

\subsubsection{Polyglycerol}

Polyglycerol is a hyperbranched polymer that is characterized by the combination of a stable, biocompatible polyether having high-end group functionality and a compact, well-defined dendrimer-like structure. These characteristics have been used to generate new materials properties and for biomedical applications [81]. Polyglycerol dendrimer has also been formulated as PDCs.

Nagel et al. presented a pair of theranostic polymer conjugates based on dendritic polyglycerol as a polymeric carrier and DOX as a therapeutic agent. The dendritic polyglycerol was synthesized by ROP in emulsion. DOX was conjugated to polyglycerol by different cleavable linkers, i.e., $\mathrm{pH}$-sensitive linker and protease-sensitive linker. The PDCs were then labeled by an indodicarbocyanine (IDCC) dye. The size of the PDCs with a $\mathrm{pH}$-sensitive linker was $9.2 \mathrm{~nm}$, and that of the protease-sensitive linker was $9.7 \mathrm{~nm}$. The PDCs enabled the study of drug release triggered by the acidic $\mathrm{pH}$ or by enzymatic action. The release profile of DOX was studied by tracking the fluorescence recovery in a cell-based high throughput microplate assay. The DOX release profile along with the cytotoxicity of conjugates, demonstrated the applicability of the conjugate as a theranostic agent. The $\mathrm{pH}$-cleavable linker was found to be more suitable for drug delivery because the enzyme-sensitive linker showed premature drug release. This $\mathrm{pH}$-sensitive PDC could show a pronounced effect on the treatment of multidrug-resistant cell lines as well [59].

\subsubsection{Polyglutamic Acid}

Polyglutamic acid (PGA) is a water-soluble and biodegradable biopolymer that is well-tolerated in high doses. PGA is composed of naturally occurring L-glutamic acid linked together through amide bonds. Molecules can be conjugated to the pendant carboxyl groups in each L-glutamic repeating unit producing drug-polymer conjugates. In general, poly ( $\alpha$-glutamic acid) is mostly utilized to develop PDCs due to better reactivity of free carboxylic acid group and availability of polymer. Poly ( $\alpha$-glutamic acid) is most often synthesized via ROP of $N$-carboxyanhydride (NCA) of $\gamma$-benzyl-L-glutamate [82].

Dai et al. developed a self-assembled star-shaped porphyrin-cored PLG conjugate (SPLGA) via a ring-opening polymerization for tumor targeting and enhanced PDT. The incorporation of the efficient fluorescent probe made it possible to monitor the cell uptake and drug-delivery pathway. This $\mathrm{pH}$-responsive nanocarrier with a hydrodynamic radius 
of $107 \mathrm{~nm}$ measured with dynamic light scattering (DLS) showed promising tumor-selective photosensitizing activity for PDT due to porphyrin, generating singlet oxygen $\left({ }^{1} \mathrm{O}_{2}\right)$ that damages malignant cells [60].

DOX is a highly potent drug used in cancer therapy, but one major limitation for its use is the cardiotoxicity of the drug [83]. Panwar et al. utilized the drug-conjugate approach to prevent the DOX-induced cardiotoxicity, which was visualized by the non-invasive anti-myosin approach using Tc-99m-labeled polymers. DOX conjugated with PGA via peptide bonds to the carboxylic acids was used in this study as a safer alternative to free DOX. Early detection of DOX-induced cardiotoxicity using bispecific anti-myosin antibody complex-based radiolabeled (Tc-99m) polylysine polymer was successfully demonstrated and was suggested as a better alternative to traditionally used In-111-labeled polymers. Authors also suggested that radioisotopes can be easily substituted with a drug to produce theranostic materials [61].

\subsection{Natural Polymers in Nanotheranostic Agent Design}

\subsubsection{Albumin}

Traditionally, human serum albumin (HSA) has been used as a blood supplement for the maintenance and restoration of blood volume. However, lately, the use of albumin as drug nanocarriers has increased. HSA exhibits qualities like biocompatibility, a long half-life, low cost, excellent stability, and easy preparation. Further, it has been shown to accumulate within the tumor environment or the inflamed tissues making it a versatile drug carrier $[84,85]$.

The slightly acidic $\mathrm{pH}$ and hypoxicity of the tumor microenvironment (TME) benefit the tumor but are detrimental for oxygen-dependent treatments like photodynamic therapy (PDT) and radiotherapy [86]. To overcome this obstacle and many more, Wu et al. integrated iridium oxide $\left(\mathrm{IrO}_{2}\right)$-manganese dioxide $\left(\mathrm{MnO}_{2}\right)$ into chlorine e6 (Ce6)-conjugated bovine serum albumin (BSA), yielding uniform BSA-Ce6@ $\mathrm{IrO}_{2} / \mathrm{MnO}_{2}$ nanoparticles with a diameter of around $110 \mathrm{~nm}$ to act as a nanotheranostic agent. Nanoparticles were fabricated by first conjugating the hydrophobic photosensitizer Ce6 to BSA and then adding $\operatorname{Ir}^{3+}$ and $\mathrm{Mn}^{2+}$ through biomineralization. The presence of $\mathrm{IrO}_{2}$ gives high photothermal conversion efficacy and makes it an excellent contrast agent for computed X-ray tomography (CT). Further, the high NIR absorption provides possibilities for photoacoustic (PA) and photothermal imaging. $\mathrm{MnO}_{2}$ in the composite can produce $\mathrm{O}_{2}$ by decomposing $\mathrm{H}_{2} \mathrm{O}_{2}$ overcoming the hypoxia, thus enhancing the efficacy of PDT, and the released $\mathrm{Mn}^{+}$ions can act as contrast agents for magnetic resonance imaging (MRI). In vitro and in vivo evaluation showed that this multifunctional nanotheranostic is an "all in one system" offering highly effective synergistic therapy for photothermal therapy (PTT), PDT, and excellent CT/MRI/PA trimodal imaging (Figure 3) [62].

Breast cancer consists of several subtypes, and one of them is triple-negative breast cancer (TNBC), which is associated with a poor prognosis due to lack of targeted therapy $[87,88]$. Hafner et al. designed an HSA and polyethylene glycol (PEG) copolymer by denaturizing, cationizing, and PEGylating HSA biopolymers. This copolymer was then incorporated with $27 \mathrm{pH}$-controlled hydrazone-linked DOX molecules for targeted release in an acidic environment and 44 copies of the covalently-attached MRI agent gadolinium (III) (Gd(III)) producing dcHSA-Gd-DOX. The prepared biodegradable albumin-based nanocarriers with a size of $87.8 \pm 2.3$ (measured with DLS in DPBS) exhibited TNBC tissue selectivity with high cell toxicity, low systemic toxicity, and high-contrast MR imaging [63]. 


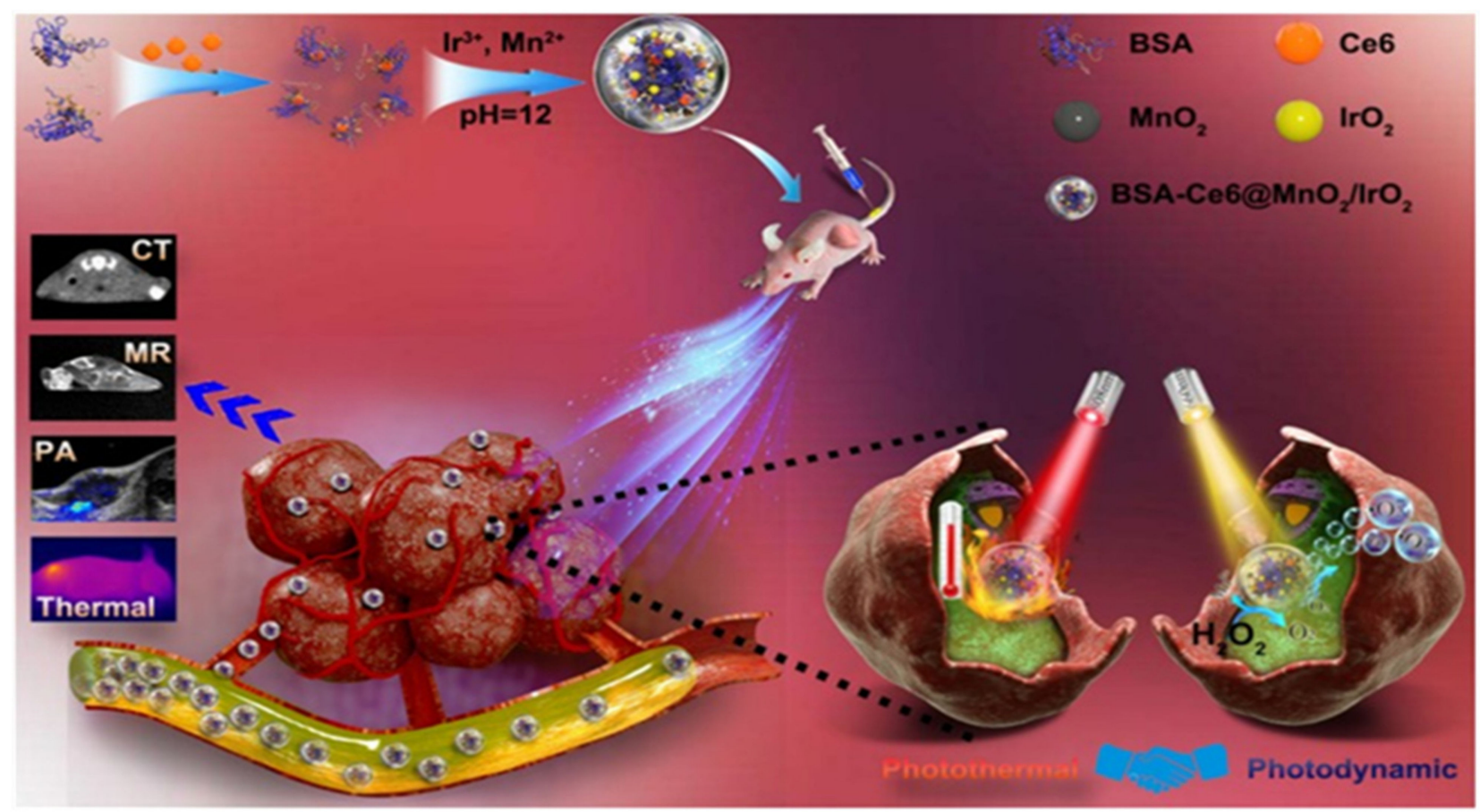

Figure 3. Schematic illustration of multiple bioimaging-guided tumor photodynamic therapy (PDT) and photothermal therapy (PTT) using BSA-Ce6@IrO2/MnO2 [62].

\subsubsection{Gelatin}

Natural, biodegradable, non-toxic, and cost-effective gelatin is obtained by acid, alkaline, or enzymatic hydrolysis of collagen. Molecules with carboxylic acids can covalently be bonded with an amide bond to the amino groups present on the polymer's surface to make gelatin useful for therapeutic applications [89]. For the treatment of antibiotic-resistant microbial infections, antimicrobial photodynamic therapy (aPDT) has emerged [90]. Kirar et al. conjugated gelatin nanoparticles (GNPs) and porphyrins (por) through covalent amide bonds, obtaining tABporGNP for aPDT applications. The primary therapeutic effect of this nano-sized $(<200 \mathrm{~nm}$ ) biocompatible and biodegradable phototheranostic agent (PTNA) with luminescence properties was microbial cell death by ROS [64].

\subsubsection{Alginate}

Sodium alginate is a polyanionic polysaccharide-based natural polymer extracted from brown algae. It is biocompatible, biodegradable, highly hydrophilic, non-toxic, with easily controlled physical properties, and low cost, and therefore it has extensively been used in biotechnological and pharmaceutical applications [91].

In a recent study, Deshpande et al. designed and produced a dual-stage polysaccharidebased supramolecular nanotheranostic agent (SPN) that enables co-delivery of PI103 (PI3K/mTOR inhibitor) and a kinase inhibitor-function responsive activatable probe. The SPN was constructed through a two-stage self-assembly approach. In the first step, a standard solid-phase synthesis protocol was used to synthesize an activable probe with the peptide sequence (GK-DEVD-APC), a FRAT pair including a dye (5FAM), and a quencher on either side of the peptide sequence. By using carbodiimide chemistry, this probe was conjugated to an alginate backbone. A cationic $\beta$-cyclodextrin-inhibitor complex was prepared through self-assembly with the probe, producing SPN. The size of the SPN was determined by DLS technique to be around $200 \mathrm{~nm}$. With this SPN, significant kinase inhibition and caspase-mediated apoptosis of cancer cells were observed with real-time monitoring of fluorescence tracking of the kinase inhibition [65].

Jia et al. prepared small spherical theranostic nanoparticles mPEG-OAL-DOX/Cdots with a particle size of $27.3 \pm 2.9 \mathrm{~nm}$ for the treatment of cancer. Fluorescent carbon dots 
(Cdots) were crosslinked to the PEGylated oxidized alginate (mPEG-OAL) before DOX was conjugated by acid-labile Schiff base linkage. Site-specific and tumor-targeted drug release was achieved due to the use of a pH-triggered Schiff base linker, which acted as an "on-off" switch. Imaging-guided drug delivery in tumor therapy was enabled by the incorporation of the fluorescent Cdots [66].

\subsubsection{Chitosan}

Chitosan is a natural polysaccharide composed of glucosamine and $N$-acetylglucosamine produced by deacetylation of chitin. The polymer has a positive charge due to one primary amino group in the repeating glycosidic residue. These primary amino groups provide reactive sites for biofabrication. Chitosan's nontoxicity, biocompatibility, biodegradability, and possibilities to be modified for different purposes make it an excellent option to be used as a therapeutic carrier [92].

$\mathrm{Wu}$ et al. prepared a folate receptor-targeting theranostic nanoprobe (PPa/FITCSWCNT-FA) for cancer cell targeting and fluorescence imaging-guided photodynamic therapy. Polyethylene-glycol-modified single-walled carbon nanotubes (SWCNTs) were used as the base to produce the nanoprobes. The tumor-homing molecule folic acid (FA) and the photosensitizing drug pyropheophorbide (PPa) were conjugated by covalently linking the carboxyl group with the amino group of chitosan. As a fluorescent label, fluorescein isothiocyanate (FITC) was attached through covalent linkage. The study showed that $\mathrm{PPa} /$ FITC-SWCNT-FA could specifically target folate-receptor overexpressing cancer cells. The imaging ability is based on fluorescence imaging, and the therapy ability is based on photo-activation of PPa to generate cytotoxic singlet oxygen resulting in tumor necrosis and apoptosis [67].

In a recent study, the carboxyl group of the hydrophobic bilirubin was conjugated to the amine group of chitosan using EDC-NHS chemistry to produce an amphiphilic chitosanbilirubin-based (Chi-Bil) nanoparticle with a particle size of $\sim 230 \mathrm{~nm}$. This nanoparticle was then loaded with the hydrophobic losartan to produce ChiBil-losartan micelles for the treatment of hepatic fibrosis. To obtain imaging properties, the ChiBil micelles were conjugated to fluorescent MHI-148. The potent endogenous antioxidant bilirubin with intrinsic anti-cancer and anti-inflammatory activities was in this study used as a reactive oxygen species (ROS) stimuli-responsive agent. By oxidation of bilirubin, the nanoparticle destabilizes and releases the encapsulated losartan. Decreased hepatic fibrosis was observed in both in vitro and in vivo for the combined effect of losartan and bilirubin [68].

A novel prodrug conjugate has been synthesized by Hu et al. They formulated an acid-sensitive amphipathic polymeric drug conjugate consisting of carboxymethyl chitosan as the polymeric backbone, DOX as therapeutic and imaging agent, and $p$ carboxybenzaldehyde ( $p$-CBA) as a molecular linker that connects to the DOX by imine addition chemistry. The size and morphology of the nanoparticles were studied with transmission electron microscopy (TEM) and DLS. The in vitro drug release study demonstrated a higher drug release rate in acidic conditions $(\mathrm{pH} 5)$ in comparison to higher $\mathrm{pH}$ like 6.5 and 7.4. DLS results demonstrated that the size of the nanoparticles increased as the $\mathrm{pH}$ of the solution decreased from 7.4 to 6.5 and 5.0. This might be due to the acid liability of the prodrug, such that a slightly acidic environment ruptured the imine and caused an enlargement in the particle size. Also, carboxymethyl chitosan chains might coagulate in acidic conditions contributing to the increase in size. The in vitro cytotoxicity study showed that the conjugates exhibited a more pronounced anti-cancer effect compared to the free DOX. The cellular uptake was characterized using confocal laser scanning microscopy, which showed an increase in fluorescence over time. This could imply that the conjugates could efficiently deliver and release DOX in the cancer cells. This $\mathrm{pH}$-sensitive prodrug could have a certain potential for cancer therapy along with imaging [69]. Gabano et al. suggest that the chitosan nanoparticle conjugated with the chemotherapeutic agent cisplatin and the photosensitizer $\operatorname{Re}(\mathrm{I})$ tricarbonyl complex could be used as a theranostic by replacing the fac- $[\operatorname{Re}(\mathrm{CO}) 3]^{+}$by the congener fac- $[99 \mathrm{mTc}(\mathrm{CO}) 3]^{+}$core [93]. 


\subsubsection{Hyaluronic Acid}

Hyaluronic acid (HA) is a polysaccharide naturally present in the extracellular matrix and the synovial fluid. It is composed of alternating units of D-glucuronic acid and $\mathrm{N}$-acetyl-D-glucosamine. HA's properties of being a biodegradable, biocompatible, nontoxic, and non-immunogenic polymer have made it widely explored for pharmaceutical purposes. Furthermore, HA naturally targets the CD44-receptor, which is over-expressed in several types of cancer cells, complemented by showing improved efficacy of some anti-cancer drugs, which has made it into an interesting polymer to study as a carrier for chemotherapy [94].

Gemcitabine (Gem) is a highly potent anti-cancer drug in the treatment of several solid tumors. However, rapid deamination had led to a short half-life, increasing the need for multiple administrations, decreasing its clinical benefit [95]. Novel tripodal HA conjugates were designed for in vitro and in vivo therapy and imaging. HA was individually conjugated via amide coupling to gemcitabine, $4^{\prime}$-(aminomethyl) fluorescein hydrochloride (4'-AMF), or tris(hydroxypyridinone) amine (THP) to produce HA-Gem for cancer therapy, HA-4'-AMF for in vitro tracking, and HA-THP for single-photon emission computed tomography/computed tomography (SPECT/CT) imaging. The study showed that the HA-Gem conjugates were safe, more stable, and compared to the free drug, an improved therapeutic efficacy against CD44 expressing tumors in lower doses was obtained [70].

Yang et al. produced a multifunctional nanotheranostic agent for targeted PTT under NIR fluorescence/MR bimodal imaging guidance. The nano-agent was obtained by conjugating HA and BSA-modified CuInS2-ZnS quantum dots onto the surface of PEI-coated magnetic iron oxide Prussian Blue nanoparticles to get FPPBH NPs. The obtained NPs with a size of around $140 \mathrm{~nm}$ showed good biocompatibility, great adsorption in the NIR region, strong NIR fluorescence, improved uptake by CD44 overexpressed HeLa cells, and tumor growth inhibition [71].

\subsubsection{Hydroxyethyl Starch}

Hydroxyethyl starch (HES) is a modified polymer used as plasma volume replacement. HES is a polysaccharide obtained from natural maize or potato starch, which is a polymer of glucose. HES polymer is biocompatible, biodegradable, low immunogenic, and can be readily modified by various functional moieties, making it an attractive material in drug delivery [96].

In a recent study, HES was utilized as a polymer carrier to deliver paclitaxel (PTX) selectively into the tumor region. The conjugate was prepared by using di-sulfide as a redoxresponsive linker, which successfully self-assembled into core-corona structure owing to the hydrophobicity of the drug. To impart imaging possibility and to make the prepared nanoparticle theranostic, a fluorophore 1,1-dioctadecyl-3,3,3,3-tetramethylindotricarbo cyanine iodide $(\mathrm{DiR})$ was loaded into the particles using the dialysis method. The prepared nanoparticles (DHP) with a size of $160 \pm 7.8 \mathrm{~nm}$ were evaluated on tumor-bearing mice for dual stimuli-responsive release with imaging possibility. The encapsulation of DiR in nanoparticles causes fluorescence quenching, but an increase in fluorescence intensity was observed in the reductive environment owing to the cleavage of disulfide bonds. The disruption of the disulfide linkage in the glutathione-rich tumor region resulted in the collapse of the core-corona structure, leading to the release of PTX and DiR (Figure 4). This unique property offers ON-OFF imaging (fluorescence + photoacoustic) with the selective release of PTX along with the possibility of photothermal therapy [72].

Following a similar approach, Yu et al. prepared DOX-conjugated HES-based NPs loaded with ICG. DOX was conjugated to HES through a redox-sensitive disulfide linker (HES-SS-DOX), which readily self-assembled in aqueous media in the presence of ICG to yield HES-SS-DOX@ICG NPs. The activity of the prepared nanotheranostic was based on DOX as a chemotherapeutic agent and ICG as both an imaging and a photothermal agent for chemo-phototherapy. The prepared NPs were expected to have a particle size 
around $10 \mathrm{~nm}$, but the obtained particle size was between 100 and $200 \mathrm{~nm}$, indicating aggregate formation due to ICG. NPs with good physical and photothermal stability, high photothermal efficiency, and redox-sensitive release of DOX demonstrated complete eradication of tumors with only one dose of NPs and one single laser irradiation at the tumor site [73].

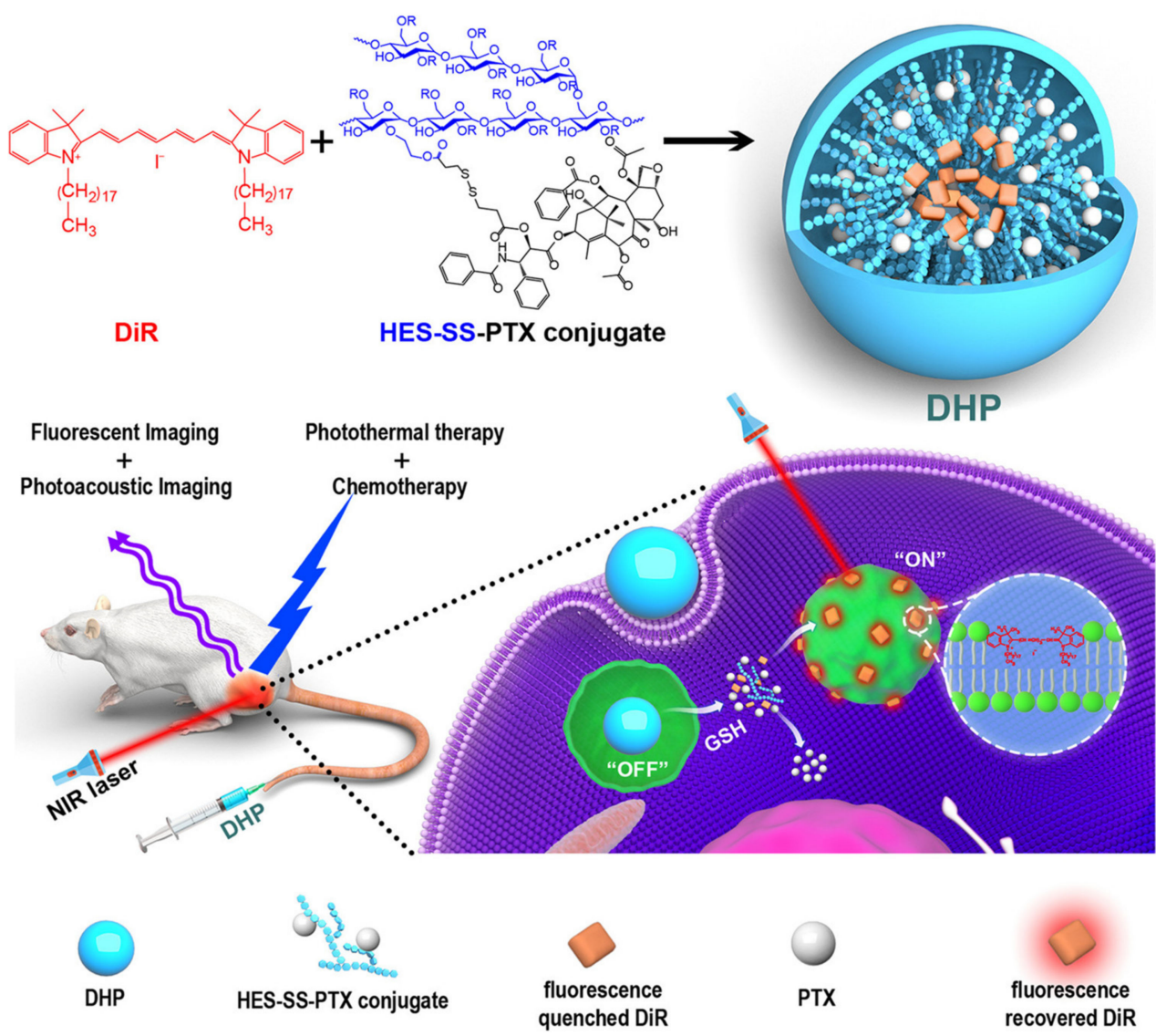

Figure 4. Pictorial presentation of the preparation of DHP nanoparticle and its multiple theranostic applications. Reproduced with permission from Reference [72]. Copyright (2019) American Chemical Society.

\section{Outlook}

Polymer drug conjugates are indeed an emerging concept in drug delivery, which offers several advantages such as sustained and targeted drug release, enhanced aqueous solubility and safety of drugs, and so forth. Moreover, this approach provides a unique opportunity for the formulation of either nano-sized drug-delivery systems or conventional dosage forms, e.g., tablet/capsule such as Movantik ${ }^{\circledR}$. Premature drug release before reaching the target is one of the major factors directly linked to the suboptimal activities of nanotechnology-based drug-delivery systems. Using PDCs as nanocarriers is undoubtedly the solution to this problem, and owing to these advantages, several formulations based on PDCs are already in clinical trials. Consequently, the addition of theranostic characteristics to PDCs has recently been explored with the objective to enhance the overall performance of these systems. With the aid of theranostic characteristics, it is possible to diagnose and treat the disease with a single nanocarrier, which most possibly reduces the treatment cost and improves patient compliance.

Moreover, tracing the biodistribution of nanocarriers is feasible in the presence of an imaging dye, which could be especially helpful in cases of external stimuli-responsive nanocarriers. For instance, after administering PDCs, clinicians can follow the distribution and activate the drug or photosensitizer agent precisely at the target site, such as a tumor. 
However, it is highly possible to get a false impression while using encapsulated imaging moieties because a lot of encapsulated guest molecules could be released before reaching the target site, thus disturbing the intended signal [97]. In such a situation, imaging moieties would deposit in the excretion organs much faster compared to nano-sized systems, which are often designed with the property of long blood circulation. In turn, the advantages of nanotheranostics would not be fully attained due to the separation of imaging moiety and PDCs. In our opinion, the imaging agent conjugated with a polymer might yields better and more precise results, especially in the case of drug-delivery systems designed for external activation.

Nevertheless, PDC-based nanotheranostics are in the early development phase, and extensive research is warranted to establish them as potential therapeutic agents. More emphasis on polymer degradation, toxicity, excretion, etc., should be given in future studies. These parameters are of utmost importance and are required by the regulatory agencies for successful clinical translation.

Author Contributions: Conceptualization, K.K.B.; writing-original draft preparation, S.M. and E.S.; writing-review and editing, J.B., J.M.R., and K.K.B. All authors have read and agreed to the published version of the manuscript.

Funding: The authors acknowledge the funding support from the Sigrid Jusélius Foundation, Academy of Finland (\#309374), Erasmus+ Programme of the European Union (EACH EM JMD, project No 586571) and Tor, Joe och Pentti Borgs minnesfond 2020.

Conflicts of Interest: The authors declare no conflict of interest.

\section{References}

1. Qian, C.G.; Chen, Y.L.; Feng, P.J.; Xiao, X.Z.; Dong, M.; Yu, J.C.; Hu, Q.Y.; Shen, Q.D.; Gu, Z. Conjugated polymer nanomaterials for theranostics. Acta Pharmacol. Sin. 2017, 38, 764-781. [CrossRef] [PubMed]

2. Larson, N.; Ghandehari, H. Polymeric conjugates for drug delivery. Chem. Mater. 2012, 24, 840-853. [CrossRef] [PubMed]

3. Chang, M.; Zhang, F.; Wei, T.; Zuo, T.; Guan, Y.; Lin, G.; Shao, W. Smart linkers in polymer-drug conjugates for tumor-targeted delivery. J. Drug Target. 2016, 24, 475-491. [CrossRef] [PubMed]

4. Das, S.S.; Bharadwaj, P.; Bilal, M.; Barani, M.; Rahdar, A.; Taboada, P.; Bungau, S.; Kyzas, G.Z. Stimuli-responsive polymeric nanocarriers for drug delivery, imaging, and theragnosis. Polymers 2020, 12, 1397. [CrossRef]

5. Feng, Q.; Tong, R. Anticancer nanoparticulate polymer-drug conjugate. Bioeng. Transl. Med. 2016, 1, 277-296. [CrossRef]

6. Alven, S.; Nqoro, X.; Buyana, B.; Aderibigbe, B.A. Polymer-Drug Conjugate, a Potential Therapeutic to Combat Breast and Lung Cancer. Pharmaceutics 2020, 12, 406. [CrossRef]

7. Thakor, P.; Bhavana, V.; Sharma, R.; Srivastava, S.; Bala Singh, S.; Kumar Mehra, N. Polymer-drug conjugates: Recent advances and future perspectives. Drug Discov. Today 2020, 25, 1718-1726. [CrossRef]

8. Ekladious, I.; Colson, Y.L.; Grinstaff, M.W. Polymer-drug conjugate therapeutics: Advances, insights and prospects. Nat. Rev. Drug Discov. 2019, 18, 273-294. [CrossRef]

9. Chawla, S.P.; Goel, S.; Chow, W.; Braiteh, F.; Singh, A.S.; Olson, J.E.G.; Osada, A.; Bobe, I.; Riedel, R.F. A Phase 1b Dose Escalation Trial of NC-6300 (Nanoparticle Epirubicin) in Patients with Advanced Solid Tumors or Advanced, Metastatic, or Unresectable Soft-tissue Sarcoma. Clin. Cancer Res. 2020, 26, 4225-4232. [CrossRef] [PubMed]

10. Peng, H.; Liu, X.; Wang, G.; Li, M.; Bratlie, K.M.; Cochran, E.; Wang, Q. Polymeric multifunctional nanomaterials for theranostics. J. Mater. Chem. B 2015, 3, 6856-6870. [CrossRef]

11. Zhao, J.; Chen, J.; Ma, S.; Liu, Q.; Huang, L.; Chen, X.; Lou, K.; Wang, W. Recent developments in multimodality fluorescence imaging probes. Acta Pharm. Sin. B 2018, 8, 320-338. [CrossRef]

12. Wallyn, J.; Anton, N.; Akram, S.; Vandamme, T.F. Biomedical Imaging: Principles, Technologies, Clinical Aspects, Contrast Agents, Limitations and Future Trends in Nanomedicines. Pharm. Res. 2019, 36, 1-31. [CrossRef]

13. Denk, W.; Strickler, J.H.; Webb, W.W. Two-photon laser scanning fluorescence microscopy. Science 1990, 248, 73-76. [CrossRef] [PubMed]

14. Zou, C.; Wu, B.; Dong, Y.; Song, Z.; Zhao, Y.; Ni, X.; Yang, Y.; Liu, Z. Biomedical photoacoustics: Fundamentals, instrumentation and perspectives on nanomedicine. Int. J. Nanomed. 2016, 12, 179-195. [CrossRef]

15. Krasia-Christoforou, T.; Georgiou, T.K. Polymeric theranostics: Using polymer-based systems for simultaneous imaging and therapy. J. Mater. Chem. B 2013, 1, 3002-3025. [CrossRef]

16. Duncan, R.; Vicent, M.J. Polymer therapeutics-prospects for 21st century: The end of the beginning. Adv. Drug Deliv. Rev. 2013, 65, 60-70. [CrossRef] [PubMed]

17. Atkinson, S.P.; Andreu, Z.; Vicent, M.J. Polymer therapeutics: Biomarkers and new approaches for personalized cancer treatment. J. Pers. Med. 2018, 8, 6. [CrossRef] 
18. Lee, H.J.; Ponta, A.; Bae, Y. Polymer nanoassemblies for cancer treatment and imaging. Ther. Deliv. 2010, 1, 803-817. [CrossRef] [PubMed]

19. Xiong, Y.; Jiang, W.; Shen, Y.; Li, H.; Sun, C.; Ouahab, A.; Tu, J. A Poly (g,L-glutamic acid)-citric acid based nanoconjugate for cisplatin delivery. Biomaterials 2012, 33, 7182-7193. [CrossRef] [PubMed]

20. Bansal, K.; Sasso, L.; Makwana, H.; Awwad, S.; Brocchini, S.; Alexander, C. Nanopharmacy: Exploratory Methods for Polymeric Materials. In Pharmaceutical Nanotechnology: Innovation and Production; Wiley-VCH Verlag GmbH \& Co. KGaA: Weinheim, Germany, 2016; pp. 231-270.

21. Bhatia, S.; Bhatia, S. Natural Polymers vs Synthetic Polymer. In Natural Polymer Drug Delivery Systems; Springer International Publishing: Cham, Switzerland, 2016; pp. 95-118.

22. Duncan, R.; Vicent, M.J. Do HPMA copolymer conjugates have a future as clinically useful nanomedicines? A critical overview of current status and future opportunities. Adv. Drug Deliv. Rev. 2010, 62, 272-282. [CrossRef] [PubMed]

23. Knop, K.; Hoogenboom, R.; Fischer, D.; Schubert, U.S. Poly(ethylene glycol) in Drug Delivery: Pros and Cons as Well as Potential Alternatives. Angew. Chemie Int. Ed. 2010, 49, 6288-6308. [CrossRef] [PubMed]

24. Shiraishi, K.; Yokoyama, M. Toxicity and immunogenicity concerns related to PEGylated-micelle carrier systems: A review. Sci. Technol. Adv. Mater. 2019, 20, 324-336. [CrossRef]

25. Casalini, T.; Rossi, F.; Castrovinci, A.; Perale, G. A Perspective on Polylactic Acid-Based Polymers Use for Nanoparticles Synthesis and Applications. Front. Bioeng. Biotechnol. 2019, 7, 259. [CrossRef]

26. Bansal, K.K.; Kakde, D.; Purdie, L.; Irvine, D.J.; Howdle, S.M.; Mantovani, G.; Alexander, C. New biomaterials from renewable resources-amphiphilic block copolymers from $\delta$-decalactone. Polym. Chem. 2015, 6, 7196-7210. [CrossRef]

27. Sharma, S.; Parmar, A.; Kori, S.; Sandhir, R. PLGA-based nanoparticles: A new paradigm in biomedical applications. Trends Anal. Chem. 2016, 80, 30-40. [CrossRef]

28. Bansal, K.K.; Rosenholm, J.M. Synthetic polymers from renewable feedstocks: An alternative to fossil-based materials in biomedical applications. Ther. Deliv. 2020, 11, 297-300. [CrossRef]

29. Ullah, R.S.; Wang, L.; Yu, H.; Abbasi, N.M.; Akram, M.; Ul-Abdin, Z.; Saleem, M.; Haroon, M.; Khan, R.U. Synthesis of polyphosphazenes with different side groups and various tactics for drug delivery. RSC Adv. 2017, 7, 23363-23391. [CrossRef]

30. Rothemund, S.; Teasdale, I. Preparation of polyphosphazenes: A tutorial review. Chem. Soc. Rev. 2016, 45, 5200-5215. [CrossRef]

31. Pelosi, C.; Tinè, M.R.; Wurm, F.R. Main-chain water-soluble polyphosphoesters: Multifunctional polymers as degradable PEG-alternatives for biomedical applications. Eur. Polym. J. 2020, 141, 110079. [CrossRef]

32. Steinbach, T.; Wurm, F.R. Poly(phosphoester)s: A New Platform for Degradable Polymers. Angew. Chemie Int. Ed. 2015, 54, 6098-6108. [CrossRef]

33. Jafari, M.; Abolmaali, S.S.; Najafi, H.; Tamaddon, A.M. Hyperbranched polyglycerol nanostructures for anti-biofouling, multifunctional drug delivery, bioimaging and theranostic applications. Int. J. Pharm. 2020, 576, 118959. [CrossRef] [PubMed]

34. Hu, M.; Chen, M.; Li, G.; Pang, Y.; Wang, D.; Wu, J.; Qiu, F.; Zhu, X.; Sun, J. Biodegradable hyperbranched polyglycerol with ester linkages for drug delivery. Biomacromolecules 2012, 13, 3552-3561. [CrossRef]

35. Bajaj, I.; Singhal, R. Poly (glutamic acid)—An emerging biopolymer of commercial interest. Bioresour. Technol. 2011, 102, 5551-5561. [CrossRef] [PubMed]

36. Wang, H.; Taylor, W.D. Controlled Synthesis of Polyglutamic Acid. European Patent WO2011075483A1, 23 June 2011.

37. Wall, A.; Nicholls, K.; Caspersen, M.B.; Skrivergaard, S.; Howard, K.A.; Karu, K.; Chudasama, V.; Baker, J.R. Optimised approach to albumin-drug conjugates using monobromomaleimide-C-2 linkers. Org. Biomol. Chem. 2019, 17, 7870-7873. [CrossRef]

38. Karimi, M.; Bahrami, S.; Ravari, S.B.; Zangabad, P.S.; Mirshekari, H.; Bozorgomid, M.; Shahreza, S.; Sori, M.; Hamblin, M.R. Albumin nanostructures as advanced drug delivery systems. Expert Opin. Drug Deliv. 2016, 13, 1609-1623. [CrossRef]

39. Elzoghby, A.O. Gelatin-based nanoparticles as drug and gene delivery systems: Reviewing three decades of research. J. Control. Release 2013, 172, 1075-1091. [CrossRef]

40. Szekalska, M.; Puciłowska, A.; Szymańska, E.; Ciosek, P.; Winnicka, K. Alginate: Current Use and Future Perspectives in Pharmaceutical and Biomedical Applications. Int. J. Polym. Sci. 2016, 2016, 7697031. [CrossRef]

41. Bellich, B.; D'Agostino, I.; Semeraro, S.; Gamini, A.; Cesàro, A. "The good, the bad and the ugly" of chitosans. Mar. Drugs 2016, 14, 99. [CrossRef]

42. Elgadir, M.A.; Uddin, M.S.; Ferdosh, S.; Adam, A.; Chowdhury, A.J.K.; Sarker, M.Z.I. Impact of chitosan composites and chitosan nanoparticle composites on various drug delivery systems: A review. J. Food Drug Anal. 2015, 23, 619-629. [CrossRef]

43. Huang, G.; Huang, H. Application of hyaluronic acid as carriers in drug delivery. Drug Deliv. 2018, 25, 766-772. [CrossRef]

44. Fallacara, A.; Baldini, E.; Manfredini, S.; Vertuani, S. Hyaluronic Acid in the Third Millennium. Polymers 2018, 10, 701. [CrossRef]

45. Tan, R.; Wan, Y.; Yang, X. Hydroxyethyl starch and its derivatives as nanocarriers for delivery of diagnostic and therapeutic agents towards cancers. Biomater. Transl. 2020, 1, 46.

46. Zhu, X.; Anquillare, E.L.B.; Farokhzad, O.C.; Shi, J. Polymer- and Protein-Based Nanotechnologies for Cancer Theranostics. In Cancer Theranostics; Elsevier Inc.: Amsterdam, The Netherlands, 2014; pp. 419-436.

47. Koziolová, E.; Goel, S.; Chytil, P.; Janoušková, O.; Barnhart, T.E.; Cai, W.; Etrych, T. A tumor-targeted polymer theranostics platform for positron emission tomography and fluorescence imaging. Nanoscale 2017, 9, 10906-10918. [CrossRef]

48. Zhang, Y.; Hong, H.; Cai, W. PET Tracers Based on Zirconium-89. Curr. Radiopharm. 2011, 4, 131-139. [CrossRef] 
49. Yang, J.; Zhang, R.; Radford, D.C.; Kopeček, J. FRET-trackable biodegradable HPMA copolymer-epirubicin conjugates for ovarian carcinoma therapy. J. Control. Release 2015, 218, 36-44. [CrossRef]

50. Fang, J.; Šubr, V.; Islam, W.; Hackbarth, S.; Islam, R.; Etrych, T.; Ulbrich, K.; Maeda, H. N-(2-hydroxypropyl)methacrylamide polymer conjugated pyropheophorbide-a, a promising tumor-targeted theranostic probe for photodynamic therapy and imaging. Eur. J. Pharm. Biopharm. 2018, 130, 165-176. [CrossRef]

51. Cai, H.; Wang, X.; Zhang, H.; Sun, L.; Pan, D.; Gong, Q.; Gu, Z.; Luo, K. Enzyme-sensitive biodegradable and multifunctional polymeric conjugate as theranostic nanomedicine. Appl. Mater. Today 2018, 11, 207-218. [CrossRef]

52. Hou, W.; Xia, F.; Alves, C.S.; Qian, X.; Yang, Y.; Cui, D. MMP2-Targeting and Redox-Responsive PEGylated Chlorin e6 Nanoparticles for Cancer Near-Infrared Imaging and Photodynamic Therapy. ACS Appl. Mater. Interfaces 2016, 8, 1447-1457. [CrossRef]

53. Kumar, A.; Mastren, T.; Wang, B.; Hsieh, J.T.; Hao, G.; Sun, X. Design of a Small-Molecule Drug Conjugate for Prostate Cancer Targeted Theranostics. Bioconjug. Chem. 2016, 27, 1681-1689. [CrossRef]

54. Qi, R.; Wang, Y.; Bruno, P.M.; Xiao, H.; Yingjie, Y.; Li, T.; Lauffer, S.; Wei, W.; Chen, Q.; Kang, X.; et al. Nanoparticle conjugates of a highly potent toxin enhance safety and circumvent platinum resistance in ovarian cancer. Nat. Commun. 2017, 8, 2166. [CrossRef] [PubMed]

55. Hu, X.; Wang, R.; Yue, J.; Liu, S.; Xie, Z.; Jing, X. Targeting and anti-tumor effect of folic acid-labeled polymer-Doxorubicin conjugates with pH-sensitive hydrazone linker. J. Mater. Chem. 2012, 22, 13303-13310. [CrossRef]

56. Chatterjee, M.; Maity, R.; Das, S.; Mahata, N.; Basu, B.; Chanda, N. Electrospray-based synthesis of fluorescent poly(d,l-lactide-coglycolide) nanoparticles for the efficient delivery of an anticancer drug and self-monitoring its effect in drug-resistant breast cancer cells. Mater. Adv. 2020, 1, 3033-3048. [CrossRef]

57. Jun, Y.J.; Park, J.H.; Avaji, P.G.; Park, K.S.; Lee, K.E.; Lee, H.J.; Sohn, Y.S. Design of theranostic nanomedicine (Ii): Synthesis and physicochemical properties of a biocompatible polyphosphazene-docetaxel conjugate. Int. J. Nanomedicine 2017, 12, 5373-5386. [CrossRef]

58. Pei, P.; Sun, C.; Tao, W.; Li, J.; Yang, X.; Wang, J. ROS-sensitive thioketal-linked polyphosphoester-doxorubicin conjugate for precise phototriggered locoregional chemotherapy. Biomaterials 2019, 188, 74-82. [CrossRef]

59. Nagel, G.; Tschiche, H.R.; Wedepohl, S.; Calderón, M. Modular approach for theranostic polymer conjugates with activatable fluorescence: Impact of linker design on the stimuli-induced release of doxorubicin. J. Control. Release 2018, 285, $200-211$. [CrossRef]

60. Dai, X.-H.; Yang, W.-H.; Wu, C.; Jin, H.; Chang, D.-D.; Dai, Y.-R.; Pan, J.-M.; Yan, Y.-S. Synthesis and Characterization of Star-Shaped Porphyrin-cored Poly (Glutamic Acid) Conjugates as Highly Efficient Photosensitizers. J. Photopolym. Sci. Technol. 2016, 29, 823-832. [CrossRef]

61. Panwar, R.; Bhattarai, P.; Patil, V.; Gada, K.; Majewski, S.; Khaw, B.A. Imaging doxorubicin and polymer-drug conjugates of doxorubicin-induced cardiotoxicity with bispecific anti-myosin-anti-DTPA antibody and Tc-99m-labeled polymers. J. Nucl. Cardiol. 2018, 26, 1327-1344. [CrossRef] [PubMed]

62. Wu, J.; Williams, G.R.; Niu, S.; Yang, Y.; Li, Y.; Zhang, X.; Zhu, L.M. Biomineralized bimetallic oxide nanotheranostics for multimodal imaging-guided combination therapy. Theranostics 2020, 10, 841-855. [CrossRef]

63. Hafner, S.; Raabe, M.; Wu, Y.; Wang, T.; Zuo, Z.; Rasche, V.; Syrovets, T.; Weil, T.; Simmet, T. High-Contrast Magnetic Resonance Imaging and Efficient Delivery of an Albumin Nanotheranostic in Triple-Negative Breast Cancer Xenografts. Adv. Ther. 2019, 2, 1900084. [CrossRef]

64. Kirar, S.; Thakur, N.S.; Laha, J.K.; Banerjee, U.C. Porphyrin Functionalized Gelatin Nanoparticle-Based Biodegradable Phototheranostics: Potential Tools for Antimicrobial Photodynamic Therapy. Am. Chem. Soc. 2019, 2, 4202-4212. [CrossRef]

65. Deshpande, N.; Ramesh, A.; Nandi, D.; Nguyen, A.; Brouillard, A.; Kulkarni, A. Nanotheranostics Supramolecular Polysaccharide Nanotheranostics that Inhibit Cancer Cells Growth and Monitor Targeted Therapy Response. Nanotheranostics 2020, 4, 156-172. [CrossRef]

66. Jia, X.; Pei, M.; Zhao, X.; Tian, K.; Zhou, T.-T.; Liu, P. PEGylated oxidized alginate-DOX prodrug conjugate nanoparticles crosslinked with fluorescent carbon dots for tumor theranostics. ACS Biomater. Sci. Eng. 2016, 2, 1641-1648. [CrossRef]

67. Wu, B.; Zhao, N. A Targeted Nanoprobe Based on Carbon Nanotubes-Natural Biopolymer Chitosan Composites. Nanomaterials 2016, 6, 216. [CrossRef]

68. Surendran, P.S.; Thomas, R.G.; Moon, M.J.; Park, R.; Lee, J.H.; Jeong, Y.Y. A bilirubin-conjugated chitosan nanotheranostics system as a platform for reactive oxygen species stimuli-responsive hepatic fibrosis therapy. Acta Biomater. 2020, 116, 356-367. [CrossRef]

69. Hu, R.; Zheng, H.; Cao, J.; Davoudi, Z.; Wang, Q. Synthesis and in vitro characterization of carboxymethyl chitosan-CBADoxorubicin conjugate nanoparticles as pH-Sensitive drug delivery systems. J. Biomed. Nanotechnol. 2017, 13, $1097-1105$. [CrossRef]

70. Dubey, R.D.; Klippstein, R.; Wang, J.T.-W.; Hodgins, N.; Mei, K.-C.; Sosabowski, J.; Hider, R.C.; Abbate, V.; Gupta, P.N.; Al-jamal, K.T. Novel Hyaluronic Acid Conjugates for Dual Nuclear Imaging and Therapy in CD44-Expressing Tumors in Mice In Vivo. Nanotheranostics 2017, 1, 49-79. [CrossRef]

71. Yang, Y.; Jing, L.; Li, X.; Lin, L.; Yue, X.; Dai, Z. Hyaluronic Acid Conjugated Magnetic Prussian Blue@Quantum Dot Nanoparticles for Cancer Theranostics. Theranostics 2017, 7, 466-481. [CrossRef] [PubMed] 
72. Li, Y.; Wu, Y.; Chen, J.; Wan, J.; Xiao, C.; Guan, J.; Song, X.; Li, S.; Zhang, M.; Cui, H.; et al. A Simple Glutathione-Responsive Turn-On Theranostic Nanoparticle for Dual-Modal Imaging and Chemo-Photothermal Combination Therapy. Nano Lett. 2019, 19, 5806-5817. [CrossRef]

73. Yu, C.; Liu, C.; Wang, S.; Li, Z.; Hu, H.; Wan, Y.; Yang, X. Hydroxyethyl starch-based nanoparticles featured with redox-sensitivity and chemo-photothermal therapy for synergized tumor eradication. Cancers 2019, 11, 207. [CrossRef] [PubMed]

74. Fang, J.; Nakamura, H.; Maeda, H. The EPR effect: Unique features of tumor blood vessels for drug delivery, factors involved, and limitations and augmentation of the effect. Adv. Drug Deliv. Rev. 2011, 63, 136-151. [CrossRef] [PubMed]

75. Shi, Y.; van der Meel, R.; Chen, X.; Lammers, T. The EPR effect and beyond: Strategies to improve tumor targeting and cancer nanomedicine treatment efficacy. Theranostics 2020, 10, 7921-7924. [CrossRef]

76. Banerjee, S.S.; Aher, N.; Patil, R.; Khandare, J. Poly(ethylene glycol)-Prodrug Conjugates: Concept, Design, and Applications. J. Drug Deliv. 2012, 2012, 103973. [CrossRef]

77. Gou, P.; Liu, W.; Mao, W.; Tang, J.; Shen, Y.; Sui, M. Self-assembling doxorubicin prodrug forming nanoparticles for cancer chemotherapy: Synthesis and anticancer study in vitro and in vivo. J. Mater. Chem. B 2013, 1, 284-292. [CrossRef]

78. Zhu, L.; Wang, T.; Perche, F.; Taigind, A.; Torchilin, V.P. Enhanced anticancer activity of nanopreparation containing an MMP2sensitive PEG-drug conjugate and cell-penetrating moiety. Proc. Natl. Acad. Sci. USA 2013, 110, 17047-17052. [CrossRef]

79. Rezvantalab, S.; Drude, N.I.; Moraveji, M.K.; Güvener, N.; Koons, E.K.; Shi, Y.; Lammers, T.; Kiessling, F. PLGA-based nanoparticles in cancer treatment. Front. Pharmacol. 2018, 9, 1-19. [CrossRef]

80. Elzeny, H.; Zhang, F.; Ali, E.N.; Fathi, H.A.; Zhang, S.; Li, R.; El-Mokhtar, M.A.; Hamad, M.A.; Wooley, K.L.; Elsabahy, M. Polyphosphoester nanoparticles as biodegradable platform for delivery of multiple drugs and siRNA. Drug Des. Devel. Ther. 2017, 11, 483-496. [CrossRef]

81. Frey, H.; Haag, R. Dendritic polyglycerol: A new versatile biocompatible material. Rev. Mol. Biotechnol. 2002, 90, 257-267. [CrossRef]

82. Li, C. Poly(L-glutamic acid)-anticancer drug conjugates. Adv. Drug Deliv. Rev. 2002, 54, 695-713. [CrossRef]

83. Hale, J.P.; Lewis, I.J. Anthracyclines: Cardiotoxicity and its prevention. Arch. Dis. Child. 1994, 71, 457-462. [CrossRef]

84. Rahimizadeh, P.; Yang, S.; Lim, S.I. Albumin: An Emerging Opportunity in Drug Delivery. Biotechnol. Bioprocess Eng. 2020, 25, 985-995. [CrossRef]

85. Zhang, Y.; Wan, Y.; Chen, Y.; Blum, N.T.; Lin, J.; Huang, P. Ultrasound-Enhanced Chemo-Photodynamic Combination Therapy by Using Albumin “Nanoglue"-Based Nanotheranostics. Am. Chem. Soc. Nano 2020, 14, 5560-5569. [CrossRef]

86. Zhou, Z.; Song, J.; Nie, L.; Xiaoyuan, C. Reactive oxygen species generating systems meeting challenges of photodynamic cancer therapy. Chem. Soc. Rev. 2016, 45, 6597-6626. [CrossRef] [PubMed]

87. Ferlay, J.; Soerjomataram, I.; Dikshit, R.; Eser, S.; Mathers, C.; Rebelo, M.; Parkin, D.M.; Forman, D.; Bray, F. Cancer incidence and mortality worldwide: Sources, methods and major patterns in GLOBOCAN 2012. Int. J. Cancer 2015, 136, E359-E386. [CrossRef] [PubMed]

88. Collignon, J.; Lousberg, L.; Schroeder, H.; Jerusalem, G. Triple-negative breast cancer: Treatment challenges and solutions. Breast Cancer Targets Ther. 2016, 8, 93-107.

89. Foox, M.; Zilberman, M. Drug delivery from gelatin-based systems. Expert Opin. Drug Deliv. 2015, 12, 1547-1563. [CrossRef] [PubMed]

90. Liu, Y.; Qin, R.; Zaat, S.A.J.; Breukink, E.; Heger, M. Antibacterial photodynamic therapy: Overview of a promising approach to fight antibiotic-resistant bacterial infections. J. Clin. Transl. Res. 2015, 1, 140-167.

91. Guarino, V.; Caputo, T.; Altobelli, R.; Ambrosio, L. Degradation properties and metabolic activity of alginate and chitosan polyelectrolytes for drug delivery and tissue engineering applications. AIMS Mater. Sci. 2015, 2, 497-502. [CrossRef]

92. Ravi Kumar, M.N.V.; Muzzarelli, R.A.A.; Muzzarelli, C.; Sashiwa, H.; Domb, A.J. Chitosan Chemistry and Pharmaceutical Perspectives. Chem. Rev. 2004, 104, 6017-6084. [CrossRef]

93. Gabano, E.; do Queantal, L.; Perin, E.; Silva, F.; Raposinho, P.; António, P.; Ravera, M. Pt (IV)/Re (I) Chitosan Conjugates as a Flexible Platform for the Transport of Therapeutic and/or Diagnostic Anticancer Agents. Inorganics 2018, 6, 4. [CrossRef]

94. Dosio, F.; Arpicco, S.; Stella, B.; Fattal, E. Hyaluronic acid for anticancer drug and nucleic acid delivery. Adv. Drug Deliv. Rev. 2016, 97, 204-236. [CrossRef]

95. Reid, J.M.; Qu, W.; Safgren, S.L.; Ames, M.M.; Krailo, M.D.; Seibel, N.L.; Kuttesch, J.; Holcenberg, J. Phase I Trial and Pharmacokinetics of Gemcitabine in Children With Advanced Solid Tumors. J. Clin. Oncol. 2004, 22, 2445-2451. [CrossRef] [PubMed]

96. Sleightholm, R.; Yang, B.; Yu, F.; Xie, Y.; Oupický, D. Chloroquine-Modified Hydroxyethyl Starch as a Polymeric Drug for Cancer Therapy. Biomacromolecules 2018, 18, 2247-2257. [CrossRef] [PubMed]

97. Gulin-Sarfaz, T.; Pryazhnikov, E.; Zhang, J.; Rosenholm, J.M. Chemical and photonic interactions in vitro and in vivo between fluorescent tracer and nanoparticle-based scavenger for enhanced molecular imaging. Mater. Today Bio 2019, 2, 100010. [CrossRef] [PubMed] 